\title{
OPTIMALISASI TATA LETAK FASILITAS KOPERASI WANITA CAHAYA UMA HASTI DI CILODONG, DEPOK
}

\author{
Anita Nurfida*', Anggi Oktaviani \\ Program Studi Teknik Industri, Fakultas Teknik dan Ilmu Komputer, \\ Universitas Indraprasta PGRI, Indonesia \\ E-mail: nadiva87@gmail.com*, anggi.oktaviani@unindra.ac.id \\ Received: November 3, 2020 / Revised: April 23, 2021 / Accepted: April 27, 2021 \\ DOI: https://doi.org/10.36782/ijsr.v3i1.63
}

\begin{abstract}
ABSTRAK
Koperasi Wanita Cahaya Uma Hasti merupakan yang koperasi terletak di kelurahan Sukamaju, kecamatan Cilodong, kota Depok. Koperasi ini menyediakan aneka kebutuhan bahan pokok dan kebutuhan rumah tangga lainnya. Dalam penyusunan dan penataan barang yang dijual (display) pada koperasi wanita Cahaya Uma Hasti masih belum teratur dan kurang tepat sehingga menyulitkan para pelanggan dalam mengambil barang. Selain itu, pemanfaatan ruangan yang belum optimal, membuat konsumen kurang nyaman. Tujuan dari Pengabdian Masyarakat ini dengan memberikan pemahaman tentang optimalisasi tata letak fasilitas dan membuat usulan tata letak fasilitas koperasi Cahaya Uma Hasti Depok untuk memaksimalkan penataan barang yang dijual. Pelaksanaan kegiatan Abdimas ini dilakukan dalam tiga tahap, yaitu: tahap persiapan, pelaksanaan dan evaluasi. Tahap persiapan dilakukan dengan observasi langsung dan melakukan wawancara kepada seluruh pengurus koperasi, serta mempersiapkan materi yang akan disampaikan pada kegiatan abdimas. Tahap kedua yaitu tahap pelaksanaan abdimas dengan mengadakan workshop dan diskusi tentang optimalisasi tata letak fasilitas yang disesuaikan dengan kebutuhan pada koperasi wanita Cahaya Uma Hasti. Setelah itu, dilakukan tahap evaluasi kegiatan abdimas untuk mengetahui kesuksesan acara abdimas dan menyelesaikan permasalahan mitra. Setelah adanya usulan tata letak fasilitas Koperasi Wanita Cahaya Uma Hasti mendapatkan simpulan sebagai berikut: pengurus dan anggota koperasi mendapatkan pengetahuan mengenai optimalisasi tata letak fasilitas Koperasi Wanita Cahaya Uma Hasti sehingga dapat memudahkan pelanggan dalam berbelanja, dan penataan barangbarang yang ada di Koperasi Wanita Cahaya Uma Hasti menjadi maksimal dan memudahkan pengurus dalam memasukkan barang ke dalam koperasi.
\end{abstract}

Kata kunci: Barang, Fasilitas, Koperasi, Optimalisasi, Tata Letak.

\section{ABSTRACT}

Koperasi Wanita Cahaya Uma Hasti is a cooperative located in Sukamaju sub-district, Cilodong sub-district, Depok city. This cooperative provides various basic necessities and other household needs. In the arrangement and arrangement of goods sold (display) at the Cahaya Uma Hasti women's cooperative, it is still irregular and inaccurate, making it difficult for customers to retrieve goods. In addition, space utilization is not optimal, making consumers less comfortable. The purpose of this Community Service is to provide an understanding of the optimization of the facility layout and make proposals for the layout of the Cahaya Uma Hasti Depok cooperative 
facilities to maximize the arrangement of goods sold. The implementation of this activity is carried out in three stages, namely: the preparation, implementation and evaluation stages. The preparatory stage is carried out by direct observation and conducting interviews with all cooperative managers, as well as preparing materials to be delivered at the community service activity. The second stage is the implementation of the activity by holding workshops and discussions on optimizing the layout of the facilities tailored to the needs of the Cahaya Uma Hasti women's cooperative. After that, an evaluation stage of the community service activity is carried out to determine the success of the community service event and solve partner problems. After the proposal for the layout of the Koperasi Wanita Cahaya Uma Hasti's facilities, the following conclusions were obtained: the management and members of the cooperative got knowledge about optimizing the layout of the Koperasi Wanita Cahaya Uma Hasti facility so that it can make it easier for customers to shop and organize goods in the Cahaya Wanita Cooperative. Uma Hasti is maximized and makes it easier for the management to enter goods into the cooperative.

Keywords: Cooperative, Facilities, Goods, Layout, Optimization.

\section{PENDAHULUAN}

Perekonomian Indonesia saat ini dihadapkan dengan perubahan situasi ekonomi yang dinamis, perang dagang di beberapa negara Adikuasa dan peningkatan teknologi yang turut serta mempengaruhi gejolak perekonomian dalam negeri. Masyarakat pada umumnya mengharapkan kestabilan harga bahan pokok dan kebutuhan primer lainnya, agar dapat bertahan di tengah situasi ekonomi yang begitu dinamis seperti saat ini. Oleh karena itu, koperasi hadir untuk memenuhi kebutuhan konsumsi para anggotanya dan masyarakat pada umumnya serta mengembangkan potensi ekonomi masyarakat berdasarkan atas asas kekeluargaan.

Koperasi terbentuk atas dasar inisiatif para anggotanya, sebagai wadah untuk memenuhi kebutuhan konsumsi rumah tangga dan mengembangkan potensi ekonomi masyarakat di sekitarnya. Koperasi Wanita Cahaya Uma Hasti merupakan koperasi konsumsi, yang terletak di kelurahan Sukamaju, kecamatan Cilodong, kota Depok dengan luas area sebesar $\pm 30 \mathrm{~m}^{2}$. Koperasi ini baru berjalan selama 1 tahun dan menyediakan aneka kebutuhan bahan pokok serta kebutuhan rumah tangga lainnya. Dalam penyusunan dan penataan barang yang dijual (display) pada koperasi wanita Cahaya Uma Hasti masih sederhana. Barang yang dijual belum disusun dengan baik dan disesuaikan dengan kebutuhan yang paling diminati oleh konsumen. Pengaturan tata letak (layout) fasilitas koperasi merupakan suatu cara dalam menyusun dan menempatkan fasilitas-fasilitas yang ada pada area koperasi, untuk menunjang segala kegiatan yang berlangsung didalamnya. Pengertian perencanaan fasilitas dapat dikemukakan sebagai proses perancangan fasilitas, termasuk didalamnya analisis, perencanaan, desain dan susunan fasifitas, peralatan fisik, dan manusia yang ditujukan 
untuk meningkatkan efisensi produksi dan sistem pelayanan (Purnomo, 2004). Adapun pengertian lain, tata letak fasilitas merupakan tata cara pengaturan fasilitas-fasilitas pabrik guna menunjang kelancaran proses produksi (Wignjosoebroto, 1992).

Secara garis besar tujuan perancangan fasilitas, yaitu untuk menentukan bagaimana aktivitas-aktivitas dan fasililtas-fasilitas produksi dapat diatur sedemikian rupa sehingga mampu menunjang upaya pencapaian tujuan pokok produksi secara efektif dan efisien. Secara skematis, perencanaan tata letak fasilitas pabrik dapat digambarkan sebagai berikut.

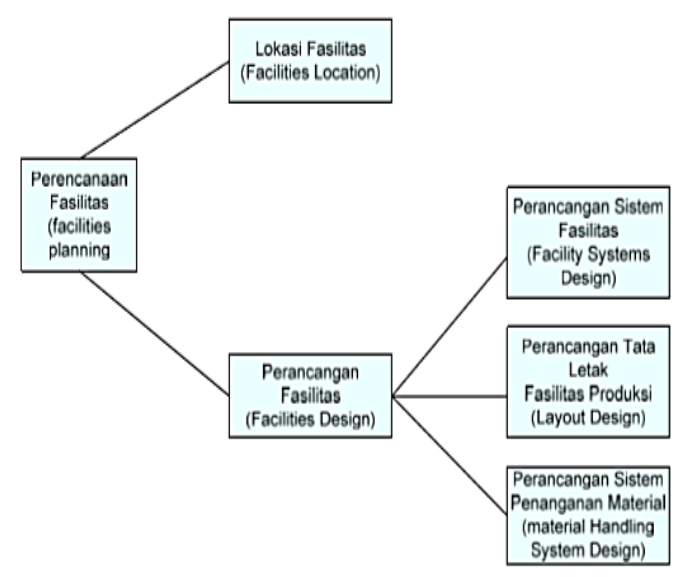

Gambar 1. Sistematika Perencanaan Fasilitas Pabrik (Sumber: Tompkins, J.A., 1996)

Pemanfaatan ruangan yang efektif dan efisien, sangat berpengaruh terhadap peningkatan penjualan ataupun omset koperasi Cahaya Uma Hasti Depok. Hal ini dikarenakan dengan penyusunan dan penataan barangbarang yang baik dapat membuat para konsumen nyaman dan mudah dalam mengambil barang yang mereka butuhkan. Selain itu, dengan penataan dan pengaturan barang yang baik membuat pelanggan baru menjadi tertarik dan ingin berbelanja di koperasi wanita Cahaya Uma Hasti Depok, sehingga akan meningkatkan keuntungan dan omset koperasi.

Beberapa permasalahan yang dihadapi oleh para pengurus dan anggota koperasi wanita Cahaya Uma Hasti Depok yaitu, kurangnya pengetahuan para pengurus dan anggota koperasi tentang pemanfaatan ruangan agar dapat berfungsi secara maksimal dalam penataan barang-barang yang dijual serta penataan barang-barang yang disediakan pada koperasi ini masih tidak teratur dan kurang tepat sehingga menyulitkan para pelanggan dalam mengambil barang. Terdapat beberapa metode yang dapat digunakan untuk menyelesaikan permasalahan ini diantaranya dengan metode Market Basket Analysis (MBA) dan metode Activity Relationship Chart (ARC). Market Basket Analysis (MBA) merupakan suatu metode analisa perilaku pelanggan dalam berbelanja pada sebuah swalayan dengan cara menemukan asosisasi dan keterkaitan diantara berbagai macam item yang diletakkan pelanggan di dalam keranjang belanjaannya (Budhi dan Soedjianto, 2021). Sedangkan Activity Relationship Chart (ARC) merupakan analisis kuantitatif yang dikembangkan oleh Muther untuk merencanakan tata letak fasilitas (Rizki, dkk., 2019).

Tujuan dari kegiatan pengabdian masyarakat ini adalah untuk memberikan pemahaman mengenai optimalisasi tata letak 
fasilitas kepada anggota koperasi wanita Cahaya Uma Hasti Depok dan Memberikan usulan tata letak fasilitas koperasi Cahaya Uma Hasti Depok untuk memaksimalkan penataan barang yang dijual.

\section{METODE KEGIATAN}

Pelaksanaan kegiatan Abdimas ini dilakukan dalam tiga tahap, yaitu: tahap persiapan, tahap pelaksanaan dan evaluasi. Tahap pertama adalah tahap persiapan. Pada tahap ini, melakukan survey lokasi mitra (observasi langsung) dan melakukan wawancara awal kepada pengurus koperasi wanita Cahaya Uma Hasti, Depok. Hal ini dilakukan untuk mengetahui secara langsung kondisi koperasi dan mengetahui target kegiatan abdimas nanti. Pada tahap ini, tim juga menyiapkan materi yang akan disampaikan nanti pada kegiatan abdimas. Beberapa metode yang ada pada optimalisasi tata letak fasilitas dikaji oleh tim dan disesuaikan dengan kebutuhan di koperasi wanita Cahaya Uma Hasti.

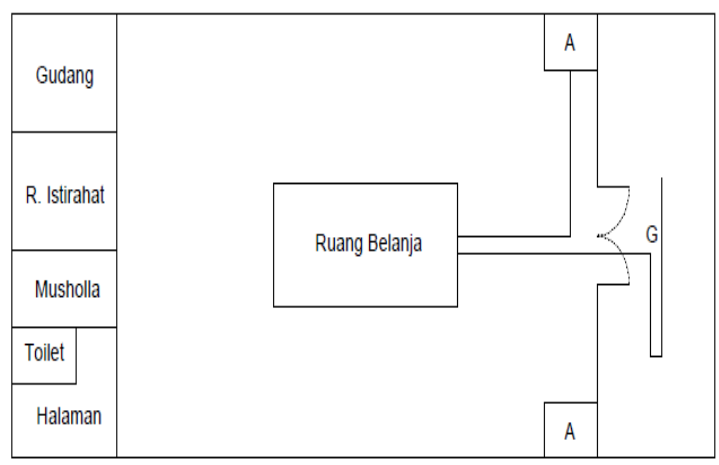

Gambar 2. Layout ruang belanja pada Koperasi Cahaya Uma Hasti

Berdasarkan perumusan masalah yang telah dikemukakan, maka dilakukan pengumpulan data-data yang digunakan dalam perancangan tata letak adalah aktivitas proses pelayanan yang terjadi di Koperasi Wanita Cahaya Uma Hasti. Data - data tersebut diantaranya: layout awal, luas lantai yang tersedia serta ukurannya, jumlah produk yang dijual, jumlah rak yang ada di koperasi dan data-data pendukung lainya yang diperlukan. Data yang diperlukan tersebut dijelaskan sebagai berikut.

Luas area yang dimiliki Koperasi Wanita Cahaya Uma Hasti sebesar $\pm 30 \mathrm{~m}^{2}$, dimanfaatkan untuk tempat menyusun barang, kasir, gudang, administrasi dan lain-lain.

Pada metode Market Basket Analysis (MBA) perlu dilakukan data mining untuk menemukan pola ataupun item apa saja yang biasanya sering dibeli pelanggan secara bersamaan (Umayah, 2015). Pada MBA terdapat istilah Assosiation rule mining yaitu merupakan aturan asosiatif antara suatu kombinasi item yang dibeli oleh pelanggan, contohnya dari aturan asosiasi dari analisa pembelian di suatu pasar swalayan dapat diketahui berapa besar kemungkinan seorang pelanggan membeli roti bersamaan dengan susu bayi (Rizki, dkk., 2019).

Dengan penerapan metode MBA dapat memberikan kemudahan bagi konsumen dalam berbelanja karena barang yang biasanya dibeli secara bersamaan berada di tempat yang berdekatan (Lestari, 2009). Bahkan dengan metode MBA ini dapat memunculkan pembelian tanpa direncanakan sebelumnya oleh pelanggan (Farkhan, 2008) 
Tahap kedua yaitu, tahap pelaksanaan abdimas atau penyuluhan (workshop). Tim pengabdi menjelaskan dan membahas secara langsung perihal penerapan optimalisasi tata letak fasilitas kepada pengurus dan anggota Koperasi Wanita Cahaya Uma Hasti Depok dengan cara memberikan pelatihan penerapan sistem penerapan Optimalisasi tata letak fasilitas.

Tahap terakhir yaitu dilakukan evaluasi terhadap kegiatan abdimas. Evaluasi berkaitan dengan kehadiran peserta, penyampaian materi dan pemahaman peserta mengenai materi yang disampaikan oleh tim. Hal ini sangat penting dilakukan untuk mengetahui kesuksesan acara abdimas dan menyelesaikan permasalahan mitra.

\section{HASIL DAN PEMBAHASAN}

Tujuan dari kegiatan pengabdian kepada masyarakat ini adala untuk meningkatkan produktivitas dengan cara pelatihan konsep tata letak fasilitas kerja dan penataan ulang tata letak fasilitas kerja koperasi Cahaya Uma Hasti. Layout sebelumnya masih belum disusun dengan baik dan disesuaikan dengan kebutuhan yang paling diminati oleh konsumen seperti yang ada di Gambar 3. Rak sabun cuci terletak di bagian kiri kasir, jauh letaknya dengan rak perlengkapan mandi dan dapur. Sehingga kami harus memberikan usulan tata letak fasilitas yang baik untuk koperasi ini seperti mendekatkan rak beras dengan buah, makanan ringan dan minuman. Pengelompokkan produk yang sejenis akan mmuahkan pengunjung untuk mencari barang yang akan dibeli atau membantu karyawan dalam melakukan pengawasan terhadap barangbarang yang dijual (Purwaningsih dkk., 2020).
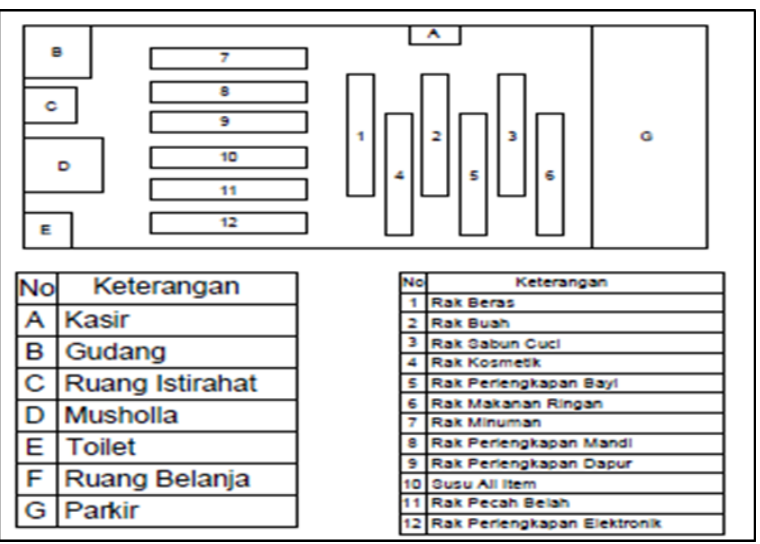

Gambar 3. Layout awal ruang belanja pada Koperasi Cahaya Uma Hasti

Adapun Operation Process Chart (OPC) dalam pelayanan koperasi Cahaya Uma Hasti adalah sebagai berikut:

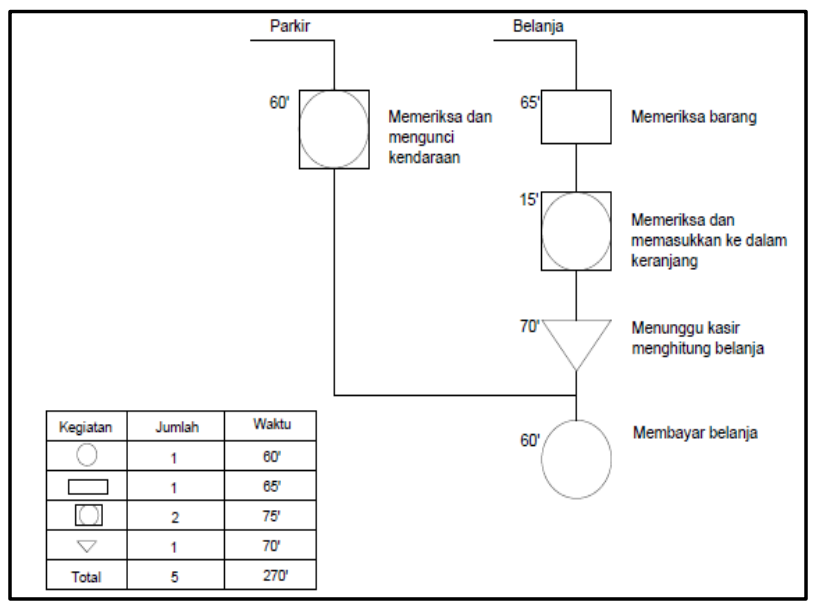

Gambar 4. Operation Process Chart pada Koperasi Cahaya Uma Hasti

Pada Gambar 4 pelanggan yang akan berbelanja di koperasi Cahaya Uma Hasti akan memarkirkan kendaraannya di ruang parkir. Kemudian pelanggan akan melihat kebutuhan yang ingin dibeli dan memeriksa barang yang ada di dalam koperasi. Jika ada, maka pelanggan akan memasukkan barang ke dalam keranjang. 
Setelah selesai memilih barang yang akan dibeli, pelanggan akan menunggu kasir untuk menghitung total belanja pelanggan dan pelanggan membayar total yang dibelanjakan. Setelah kami berdiskusi dengan para anggota dan pengurus koperasi, layout pada Gambar 3 kurang efektif dikarenakan tidak ada barang yang menarik pelanggan di dekat area kasir, dan belum adanya tata letak yang efektif dan efisien untuk Koperasi Cahaya Uma Hasti.

Tata letak yang baik dapat terwujud dengan adanya memiliki beberapa karakteristik yang jelas yang dapat dilihat bahkan dari satu pengamatan biasa. Karakteristik tata letak yang baik yang sangat penting diantaranya adalah sebagai berikut: (Apple, 1990)

a. Keterkaitan kegiatan yang terencana

b. Pola aliran barang terencana

c. Aliran yang lurus

d. Langkah balik (kembali ketempat yang telah dilalui) yang minimum

e. Jalur aliran tambahan

f. Gang yang lurus

g. Pemindahan antar operasi minimum

h. Metode pemindahan yang terencana

i. Jarak pemindahan minimum

j. Pemrosesan digabung dengan pemindahan bahan

k. Pemindahan bergerak dari penerimaan menuju pengiriman

I. Operasi pertama dekat dengan penerimaan. Beberapa poin penting yang dapat diambil dari karakteristik tata letak yang baik serta dapat kita terapkan pada koperasi wanita Cahaya Uma Hasti yaitu pola aliran yang terencana, keterkaitan kegiatan, metode pemindahan barang, jarak pemindahan minimun dan laen-lain yang dapat dipadukan dengan operation process chart pada koperasi Cahaya Uma Hasti.

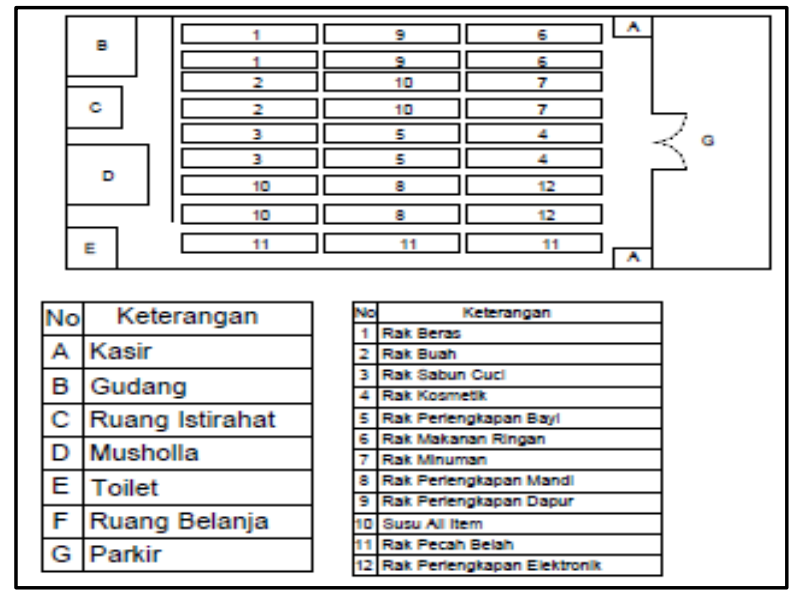

Gambar 5. Layout usulan ruang belanja pada Koperasi Cahaya Uma Hasti, Depok

Pada Gambar 5, layout usulan yang tim berikan kepada koperasi Cahaya Uma Hasti yaitu yaitu dengan memberikan ruang atau area kasir pada kedua sisi yaitu di sebelah kanan dan kiri pintu masuk agar tidak adanya antrian dalam berbelanja di Koperasi Cahaya Uma Hasti. Letak rak buah dan bahan sembako berdekatan agar tidak terkontaminasi dengan rak sabun, perlengkapan mandi dan perlengkapan rumah tangga. Rak makanan ringan di dekatkan dengan kasir agar pelanggan mudah dalam berbelanja.

\section{KESIMPULAN}

Pengaturan tata letak (layout) fasilitas koperasi merupakan suatu cara dalam menyusun dan menempatkan fasilitas-fasilitas yang ada pada area koperasi, untuk menunjang segala 
kegiatan yang berlangsung didalamnya. Beberapa permasalahan yang dihadapi oleh para pengurus dan anggota koperasi wanita Cahaya Uma Hasti Depok yaitu, kurangnya pengetahuan para pengurus dan anggota koperasi tentang pemanfaatan ruangan agar dapat berfungsi secara maksimal dalam penataan barang-barang yang dijual serta penataan barang-barang yang disediakan pada koperasi ini masih tidak teratur dan kurang tepat sehingga menyulitkan para pelanggan dalam mengambil barang. Setelah adanya usulan tata letak fasilitas Koperasi Wanita Cahaya Uma Hasti mendapatkan simpulan seperti dibawah:

1. Pengurus dan anggota koperasi mendapatkan pengetahuan mengenai optimalisasi tata letak fasilitas Koperasi Wanita Cahaya Uma Hasti sehingga dapat memudahkan pelanggan dalam berbelanja.

2. Penataan barang-barang yang ada di Koperasi Wanita Cahaya Uma Hasti menjadi maksimal dan memudahkan pengurus dalam memasukkan barang ke dalam koperasi.

\section{DAFTAR PUSTAKA}

Apple, J. M. (1990). Tata Letak Pabrik dan Pemindahan Bahan. Bandung: Penerbit ITB. Budhi, G. S dan Soedjianto, F. (2007). Aplikasi Data Mining Market Basket Analysis Pada Tabel Data Absensi Elektronik Untuk Mendeteksi Kecurangan Absensi (Check-Lock)
Karyawan di Perusahaan. Jurnal Informatika, 8(2), 119-129.

Farkhan. (2008). Desain Ulang Tata Letak di Toko Buku Ramadhan Agency Melalui Pendekatan Perilaku Konsumen dengan Metode Market Basket Analysis. Jurnal IImiah Indonesia, 5(1), $14-29$.

Lestari, T., \& Muhammad, S. (2009). Analisis Keranjang Belanja pada Data Transaksi Penjualan [Skripsi]. Institut Pertanian Bogor, Bogor.

Purnomo, H. (2004). Perencanaan dan Perancangan Fasilitas Edisi ke 1. Yogyakarta: Graha IImu.

Purwaningsih, R., Utami, T. L., Widharto, Y., \& Susanto, N. (2020). Redesain Tata Letak Produk di Supermarket Berdasarkan Perilaku Pembelian dengan Metode Market Basket Analysis. Jurnal Teknik Industri, 15(3), 196-202. Rizki, M., Devrika, D., Lubis, F. S., Silvia, dan Umam, I. H. (2019). Aplikasi Data Mining dalam Penentuan Layout Swalayan dengan Menggunakan Metode MBA. Jurnal Hasil Penelitian dan Karya IImiah dalam Bidang Teknik Industri, 5(2), 130 - 138.

Tompkins, J. (1996). Facilities Planning (2nd edition). New York: John Wiley \& Sons, INC.

Umayah, B. (2015). Aplikasi Market Basket Analysis Dengan Metode Association Rule Untuk Menemukan Perilaku Konsumen Melalui Data Transaksi (Studi Kasus : Business Center UIN Malang) [Skripsi]. Universitas Islam Negeri Maulana Malik Ibrahim, Malang. 
Indonesian Journal for Social Responsibility (IJSR) Vol. 3, No. 01, (2021), hal. 29-36

Wignjosoebroto, Sritomo. (1992). Tata Letak

Pabrik dan Pemindahan Bahan. Jakarta:

Penerbit Guna Widya. 